\title{
"Não é Chá das 5": dinâmicas de discussão e efeitos sociais do Conselho Municipal de Desenvolvimento Rural de Cachoeiras de Macacu, RJ
}

\author{
"It's not five o'clock tea": the dynamics of discussion \\ and social effects of Municipal Council of Rural \\ Development of Cachoeiras de Macacu, RJ
}

\section{Luciano Padilha dos Prazeres}

Bacharel e Mestre em Ciências Sociais pela Universidade Federal de Juiz de Fora (UFJF) e Doutor em Antropologia pelo Programa de Pós-Graduação em Antropologia da Universidade Federal Fluminense (PPGA/UFF). ID ORCID: https://orcid.org/0000-0002-4565-1275.

\section{Resumo}

Este trabalho visa à análise das dinâmicas de discussão do Conselho Municipal de Desenvolvimento Rural (CMDR) do município de Cachoeiras de Macacu, Rio de Janeiro. Para isso, atenho-me ao tema tratado nas reuniões, como o Programa Patrulha Mecanizada, programa instituído pela Secretaria Municipal de Agricultura e que objetiva a realização de obras e a oferta de serviços de maquinário agrícola para os produtores rurais. As discussões tratam da gestão do programa, da requisição de serviços pelos produtores rurais e da aquisição de maquinário agrícola pela administração municipal. $\mathrm{Na}$ análise desse tema percebo situações similares de debates, mas com distinções quanto aos meios e resultados, notadamente dos interesses postos em jogo, o que contrasta perspectivas de atendimento a produtores rurais com noções de "favorecimento", "descaso" e "atendimento político". A gestão do programa e o levantamento de demandas tornam a política agrícola inerente à secretaria e ao conselho, com a demarcação das responsabilidades para secretário municipal e para os conselheiros. A perspectiva de obtenção e uso dos maquinários incrementa essas responsabilidades ao serem atribuídos os bens, usos e seus beneficiários. Desse modo, a exploração das discussões empreendidas no CMDR demonstra a adequação de uma política agrícola de acordo com seus participantes e das perspectivas colocadas por eles em relação aos papéis dos atores e agentes mobilizados em tal debate.

Palavras-chave: Participação Popular, Conselho Municipal de Desenvolvimento Rural, Política Agrícola.

\section{Abstract}

This work aims to analyze the dynamics of discussion of Municipal Council for Rural Development of the municipality of Cachoeiras de Macacu, Rio de Janeiro. I restrict this analysis on the subject treated in meetings such as Patrol Machine Program, program instituted by the Municipal Secretary of 
Agriculture which aims the accomplish of works and the provision of agricultural machinery services to rural producers. The discussions about this subject deal with management of the program, the requisition of services by rural producers as also acquisition of agricultural machinery by municipal administration. I realize in this analyses similar situations of discussions but with distinctions as to means and results, notably of the interests put in play which contrast perspectives of services to the rural producers with notions of "advantage", "disregard" and "political aid". The management of the program and the lifting of demands make the agricultural policy inherent to the secretariat and the council with demarcation of the responsibilities for municipal secretary and the councilors. The perspective of getting and using machinery increases theses responsibilities when assigns the goods, uses and their beneficiaries. In this way, the exploration of the discussions undertaken in Municipal Council for Rural Development demonstrates the adequacy of an agricultural policy according to the set of participants of the council and the perspectives put by them regarding the roles of the actors and agents mobilized in the discussion.

Keywords: Popular Participation, Municipal Council of Rural Development, Agricultural Policy.

\section{INTRODUÇÃO}

As experiências de conselhos municipais apresentam configurações diversas e são recorrentemente analisadas quanto às suas características democratizantes e de partilha do exercício de poder (ABRAMOVAY, 2001; AVRITZER, 2010; DAGNINO, 2002; MOURA, 2005; ROMANO, DELGADO, 2002). As análises sobre os conselhos tendem a avaliá-los quanto aos aspectos democráticos e participativos, sem buscarem perceber os seus efeitos na organização social, o que gera conclusões quanto à debilidade ou incapacidade das experiências participativas em aprimorar os processos de tomada de decisão (AVRITZER, 2010; GOHN, 2011; MOURA, 2005). Em vez de avaliar, compreender as relações sociais e políticas que atravessam as experiências participativas abre novos olhares quanto à sua organização e funcionamento, especialmente sobre a reorganização das relações de poder, a inserção de segmentos populacionais nessas experiências e disputas dos significados e das modalidades da participação popular em jogo (HEREDIA et al., 2012). Tal perspectiva desloca o entendimento sobre as experiências participativas para os seus efeitos sociais.

$\mathrm{Na}$ década de 1990, o formato dos conselhos de política agrícola ou de desenvolvimento rural é impulsionado por agências estatais que perfazem ideais de democratização de espaços públicos e de descentralização das políticas públicas sob o prisma da produção agrícola (ABRAMOVAY, 2001; RO- 
MANO; DELGADO, 2002). Agências estatais, como por exemplo, o Ministério de Desenvolvimento Agrário (MDA), a Empresa Brasileira de Pesquisa Agropecuária (Embrapa) e a Empresa de Assistência Técnica e Extensão Rural (EMATER), destacam-se com a exigência ou fomento aos conselhos, promovendo-os como canais de consulta a atores sociais situados na sociedade civil e no poder público. A mobilização de repertórios ou de modelos de participação popular é alavancada com a implementação do Programa Nacional de Fortalecimento da Agricultura Familiar (Pronaf), em 1995 (ABRAMOVAY, 2001; ROMANO; DELGADO, 2002). Através do Pronaf são modelados os Conselhos Municipais de Desenvolvimento Rural, o que torna a existência do CMDR uma das prerrogativas ${ }^{1}$ para o repasse de recursos estatais para os municípios. Contudo, as experiências de conselhos de política agrícola possuem consonâncias com experiências de participação popular prévias aos marcos legais. As Comunidades Eclesiais de Base e Comissão Pastoral da Terra, associações de moradores, de trabalhadores e produtores rurais, sindicatos rurais, entre outros, servem-se de variados repertórios de envolvimento da população em processos de tomada de decisão (COMERFORD, 2003).

A regularização do município de Cachoeiras de $\mathrm{Macacu}^{2}$ ao Pronaf ocorre com mudanças gerais em um conselho existente. O Conselho Municipal de Política Agrícola e Agrária, criado por lei em 1996, é substituído em 1999 pelo Conselho Municipal de Desenvolvimento Rural³, ocasião na qual são readequados os critérios de representação, de paridade, os objetivos e seu modo de funcionamento. Em especial, a lei que institui o CMDR inaugura a representação da categoria "agricultor familiar", a qual passa a compor a divisão dos participantes com o poder público e entidades parceiras. Deste modo, os participantes do antigo conselho são realocados em novas categorias classificatórias. As associações de moradores/produtores e suas referências ter-

\footnotetext{
Além do Conselho Municipal de Desenvolvimento Rural são exigidos o Fundo Municipal de Desenvolvimento Rural e o Plano Municipal de Desenvolvimento Rural para a transferência de recursos entre os setores da administração pública (ABRAMOVAY, 2001; ROMANO; DELGADO, 2002).

2 O município de Cachoeiras de Macacu está distante da capital do estado cerca de 100 quilômetros, localizado no Leste Fluminense. Foi recentemente integrado à Região Metropolitana do Rio de Janeiro. Possui área de cerca de $900 \mathrm{~km}^{2}$ e população de cerca de 55 mil habitantes, sendo sete mil situados na zona rural.

3 Trata-se, respectivamente, da Lei Municipal no. 1.032, de 20 de março de 1996, e Lei Municipal nº. 1.246 , de 20 de outubro de 1999.
} 
ritoriais são desmembradas para compor a representação dos agricultores familiares, criando assim novas entidades aptas a integrar o CMDR. Não era incomum encontrar entre os seus componentes o trânsito entre a ocupação de cargos públicos e a direção de entidades civis. Criam-se, nessa ocasião, novas divisões territoriais, lideranças e forças políticas, além de novas condições para o exercício do poder social (HEREDIA et al., 2012).

As transformações do espaço do conselho, das categorias em disputa e das lógicas de participação foram examinadas em outro trabalho ${ }^{4}$. Neste artigo analiso as discussões que condicionam a política agrícola tal como ela é empreendida e compreendida pelos participantes do CMDR. Atenho-me a uma dimensão do seu funcionamento em que ocorrem as "disputas em torno de recursos e regras definidoras e consolidadoras de interesses específicos" (NEVES, 1993, p. 47), observando-a como "um espaço de trocas sinalizadas entre agentes, constitutivo de relações de poder instituídas em função dos recursos mobilizados" (NEVES, 2010, p. 197). As discussões empreendidas na cena do conselho ordenam os entendimentos sobre a realidade com a qual se está lidando, o que, conforme Bourdieu (2014), explicita a (di)visão do mundo social:

[...] Ter a última palavra é ter o poder sobre a representação legítima da realidade; em certos casos, impor a representação é impor a realidade quando se trata de fazer a realidade. Se você nomeia algo que até então era inominável, você o torna público, publicável [...]. O fato de tornar nominável o inominável é dar-se a possibilidade de fazê-lo existir, fazer conhecer e reconhecer, legitimar. Em inúmeros casos, o poder das palavras e o poder sobre as palavras são poderes políticos; a rigor, o poder político é em grande parte um poder pelas palavras, na medida em que as palavras são os instrumentos de construção da realidade (BOURDIEU, 2014, p. 432).

Nos termos postos na cena do conselho, é construída a responsabilidade do secretário de agricultura de atender os produtores rurais e dos conselheiros de encaminhar demandas para o secretário de agricultura. A construção dessas responsabilidades define a extensão das atribuições do conselho

4 Na tese intitulada A participação popular na gestão pública: um estudo de dois casos de conselhos municipais em Cachoeiras de Macacu-RJ, apresentada no PPGA/UFF em 2016. 
e dos papéis dos conselheiros. As discussões encenadas tratam de assuntos ou questões que estes julgam merecedoras de atenção, abordando "uma nova definição legítima de um problema público" (BOURDIEU, 2014, p. 59) através do qual é efetuada a política agrícola. O conjunto de conselheiros define a atuação do conselho face aos interesses dos produtores rurais e aos interesses da administração municipal, exercendo, assim, a encenação do drama da reflexão sobre os problemas públicos (BOURDIEU, 2014, p. 56).

Para a análise das discussões realizadas no CMDR de Cachoeiras de Macacu utilizo dados obtidos por meio de trabalho de campo realizado entre setembro de 2012 e dezembro de 2013. Nesta ocasião foram realizadas observações de reuniões, entrevistas com os participantes e coleta de documentos afins ao conselho ${ }^{5}$. O Programa Patrulha Mecanizada detém atenção destacada dos participantes do CMDR e de moradores das áreas rurais. Junto com outros assuntos, condiciona o entendimento a seu respeito como espaço "que briga", "que faz", "que chega junto", ideias que o distinguem dos demais conselhos municipais. Tal percepção desdobra-se na atuação dos participantes para terem suas demandas atendidas, para estabelecerem meios de resolução de problemas coletivos e para auxiliarem nas atividades da Secretaria Municipal de Agricultura, o que, para a população rural, é sinalizado com a indicação de conquista de benfeitorias coletivas tais como a conservação de estradas e obras de drenagem. Também significariam conquistas em torno de serviços públicos de saúde, educação e transporte, entre outros.

\section{CMDR: PRESTAR AJUDA AO MUNICÍPIO}

Os relatos dos participantes do Conselho Municipal de Desenvolvimento Rural de Cachoeiras de Macacu sobre seu processo de criação expõem

\footnotetext{
A aplicação de procedimentos flexíveis serviu para a construção dos dados aqui analisados. Para tal conduta segui as assertivas de Becker (1997), para quem "o pesquisador de campo, devido ao fato de que tem um contato contínuo com aqueles que estuda, pode coletar dados deles através de variados procedimentos, em diversos ambientes e em diferentes estados de espírito" (BECKER, 1997, p. 91). Desse modo, a coleta de dados ocorria durante o contato com participantes do conselho por meio de encontros casuais, pelo convívio durante as reuniões e pelo agendamento de entrevista ou de visita às entidades, localidades rurais e repartições públicas.

6 Os termos entre aspas, quando não reportados às citações, referem-se às categorias nativas.
} 
princípios de mobilização da população rural, notadamente a defesa de um comunitarismo da sociabilidade rural pautado na ajuda mútua, na união (COMERFORD, 2003). O histórico de mobilização dos agricultores remete a meados do século XX, com realização de mutirões para plantação, colheita, construção de benfeitorias e ajudas emergenciais, com as lutas pelo acesso e permanência na terra e salvaguarda da atividade agrícola, além da defesa dos "lavradores" face aos "fazendeiros". A união dos agricultores é remetida à organização de associação de lavradores na década de 1950, entidade pela qual foram travados embates para desapropriação de terras, assentamento dessas pessoas e para prestação de serviços de saúde, entre outros. Com o fechamento da associação de lavradores no período da Ditadura Militar, os sindicatos de trabalhadores rurais e de produtores rurais, criados vinte anos depois, tornaram-se as agências de negociação de direitos e conflitos, em especial com os processos de assentamento de agricultores na década de $1970^{7}$. Através desse histórico de mobilização, a atividade agrícola é vista pelos participantes do CMDR como de grande importância para a geração de renda no município, notadamente pela variedade de cultivos, pela manutenção de postos de trabalho e pelo abastecimento à Região Metropolitana do Rio de Janeiro.

A organização dos produtores rurais desloca-se dos espaços das associações e de sindicatos rurais para um espaço administrativo centrado na prefeitura municipal, o qual renova o status da agricultura no município. Conforme um produtor rural, Marcelo $^{8}$ (cerca de 50 anos), representante da associação de produtores de goiaba no CMDR, a Secretaria de Agricultura passa por prévia criação como departamento na administração municipal. O prefeito, um comerciante eleito nas décadas de 1960, 70 e 80, cria o Departamento de Agricultura, que é sucessivamente valorizado por demais prefeitos. Essa iniciativa é avaliada por Marcelo como "negócio que deu certo" e levou à autonomização da gestão da agricultura na estrutura da administração mu-

\footnotetext{
O município passou por experiências distintas de assentamento de agricultores. Primeiro com colonos e imigrantes japoneses em meados do século XX e, em seguida, com tentativas de criação de assentamento por parte do governo municipal na década de 1960, por parte do governo federal nos anos 1970, 80 e 90, e por parte do governo estadual nas décadas seguintes. Foi implementado, pelo governo estadual, o assentamento Serra Queimada. Pelo governo federal, o de São José da Boa Morte. O assentamento Santa Fé não foi concluído.

8 Os nomes dos atores sociais foram substituídos visando à preservação de suas identidades. No caso de indivíduos reconhecidos no cenário estadual e nacional foram mantidos os nomes.
} 
nicipal. A Secretaria de Agricultura passa a concentrar as atividades de apoio e de controle sobre os produtores rurais, o que desdobra da figura do chefe do Executivo municipal para a figura do secretário municipal a função de gerir e gestar uma área temática e um segmento populacional. Os vínculos de prefeitos e secretários de agricultura são recorrentemente identificados com as atividades agrícolas, seja pela condição de proprietário de fazenda, de produtor rural (produção de frutas) ou pela formação profissional (agrônomo, médico-veterinário). Por esses vínculos e pela atuação na secretaria e conselho são lançadas candidaturas políticas, como nas eleições municipais de 2008, em que se elegeu prefeito o médico-veterinário, o qual foi presidente do conselho e secretário de agricultura da gestão anterior (2005-2008).

Com a organização administrativa da Secretaria Municipal de Agricultura ocorre a agregação de produtores rurais junto à administração pública. De acordo com Marcelo, são esses produtores que passam a compor o Conselho de Desenvolvimento Rural:

“[...] A gente já existia mais ou menos um conselho informal. [Era] um grupo de pessoas interessadas que ia para lá se reunir, informalmente, para ajudar o município, para resolver os seus problemas. Veio a questão do governo federal falando que para a gente ter o convênio tem que ter a secretaria, tem que ter isso para eu poder mandar uma máquina, para poder... Então o programa Pronaf falou 'Não, tem que criar o conselho'. Aí foi embora, botou um monte de critério paritário."

No "conselho informal" estavam dirigentes de entidades civis, de associações, cooperativas e sindicatos rurais, parte dos quais ocupara ou viria a ocupar cargos na prefeitura e na câmara municipal. A agregação de produtores rurais junto à administração do município possibilitou a formação do Conselho Municipal de Política Agrícola e Agrária. Este não atendia aos critérios do governo federal para o repasse de recursos e foi readequado como Conselho Municipal de Desenvolvimento Rural. Além dessa adaptação, entre as "pessoas interessadas" ocorrem disputas em torno da elegibilidade da representação dos agricultores familiares.

Os produtores rurais ou as "pessoas interessadas" passam a compor o conselho sob o formato estabelecido pelo governo federal. Foram subdivididos em representantes das seguintes categorias: poder público, entidades 
parceiras e agricultores familiares. Havia três cadeiras para a primeira categoria, cinco para a segunda e 11 para a terceira. O conselho passou a atuar, conforme as atas de reuniões analisadas ${ }^{9}$, com média de 15 representantes de agricultores familiares, sete de entidades parceiras e quatro do poder público, indistintos titulares e suplentes. De acordo com Moura (2005), na formação do conselho ocorre o conflito entre grandes e pequenos proprietários quanto à sua composição. Os primeiros, representados pelo Sindicato de Produtores Rurais (SPR), abandonam o conselho, cedendo espaço para os pequenos proprietários, os quais, junto com funcionários da Secretaria de Agricultura, passam a mobilizar dirigentes de associações de moradores e produtores para atuarem na categoria "agricultor familiar". Em meados dos anos 2000, após mudança no quadro de direção, dirigentes do SPR retornam à cena do conselho como representantes das entidades parceiras.

As atribuições do conselho e dos conselheiros são detalhadas no Regimento Interno do CMDR. Dentre elas, destaco: a destinação da presidência ao secretário de agricultura; a organização formal dos produtores rurais; a definição de diretrizes, programas e investimentos; a elaboração do Plano Municipal de Desenvolvimento Rural; e a articulação em conjunto com o poder municipal de mecanismos e planos que garantam a destinação de recursos no orçamento do município para as atividades agropecuárias e agrícolas. Em relação ao Programa Patrulha Mecanizada, o Regimento Interno aponta a atribuição que têm os conselheiros de participar do planejamento dos diversos serviços de ampliação, manutenção e readequação da rede viária rural. No decorrer das reuniões, essas responsabilidades são discutidas como "papel do conselho" e "papel dos conselheiros", sendo tratadas com o sentido de prestar "ajuda ao município". O desempenho desse papel reveste as reivindicações e cobranças dos conselheiros como um modo de "prestar ajuda ao município" exatamente por informar ao secretário os problemas que emergem nas localidades rurais.

As atribuições do conselho e dos conselheiros são discutidas ao longo da reunião sob o pretexto de distintos itens de pauta. A cada item, os participantes questionam o "papel do conselheiro", o que aparece recorrentemente como "O que estamos fazendo aqui?" Durante as situações críticas,

\footnotetext{
9 As atas analisadas compreendem o período de outubro de 2009 a setembro de 2013. Nesse intervalo de tempo as reuniões ocorriam mensalmente e não houve casos de eleição do conjunto de representantes, apenas inclusão de novas entidades na categoria dos agricultores familiares.
} 
normalmente quando ocorre bate-boca ou quando um ou mais participantes apresentam ânimos exaltados, o Regimento Interno do conselho se torna objeto de consideração para ser aplicado estritamente (por exemplo: "excluir os representantes ausentes") ou para readequá-lo ("diminuir o número de representantes"). Comumente, essas situações tratam da hierarquização da participação com as definições de quem pode e quem deve integrar o conselho e também dizem respeito aos posicionamentos dos participantes com as prerrogativas sobre o que discutir e como discutir.

O conselho se reúne regularmente no auditório do prédio da prefeitura municipal, na primeira segunda-feira do mês, das 9 h30 às $12 \mathrm{~h}$. Este se localiza no centro da cidade e possui três entradas, duas delas de acesso aos corredores internos da prefeitura e uma de acesso externo. Tem espaço para cerca de oitenta pessoas com uma mesa à frente, onde se sentam presidente e secretária executiva do conselho. Demais conselheiros distribuem-se nas cadeiras, frequentemente mais próximos à mesa. Dentre 22 participantes regulares, 17 são homens e cinco são mulheres, sendo uma delas funcionária da Secretaria de Agricultura e que ocupa o cargo de secretária executiva do conselho. Os conselheiros se distribuem numa faixa etária entre 40 e 70 anos, com predominância de homens acima dos 50 anos. Durante as reuniões, os participantes tendem a formar um corpo social identificado como "nós", os "produtores rurais". Essa identificação dos conselheiros baseia-se nos vínculos de trabalho em atividades que envolvem o trato de lavoura, o cultivo de frutas, a criação de peixes e rãs, entre outras. No desenrolar das discussões, a categoria "produtor rural" acaba por se desdobrar em outras, como "agricultor", "agricultor familiar", "lavrador", "trabalhador rural", "pequeno produtor rural”, "piscicultor", "filho de agricultor" etc. Essas identificações são mobilizadas conforme o engajamento nas discussões, o que possibilita aos participantes o trânsito entre distintas posições sociais. A mobilização de vínculos valida ou justifica o ingresso e o argumento numa discussão e demonstra a teia de engajamentos pela qual essas pessoas se situam no cenário do conselho.

\section{“CHEGAR JUNTO”: DISCUSSÕES SOBRE MÁQUINAS}

Os relatos dos participantes do CMDR a respeito do Programa Patrulha Mecanizada apontam para a sua criação no ano de 2003 pelo secretário de 
agricultura. O programa é referido como "as máquinas" e "a legislação de máquinas", cujos objetivos são oferecer serviços de maquinário agrícola para os pequenos produtores e realizar obras de manutenção de estradas, drenagem de cursos d'água e construção de diques e de pequenas barragens. Uma equipe de funcionários da Secretaria Municipal de Agricultura é encarregada pela operação do maquinário, sendo um destes o "assessor de máquinas", o chefe de equipe. Esse funcionário demonstra a mediação entre as decisões tomadas na Secretaria e a execução das operações in loco. O equipamento utilizado pela Secretaria de Agricultura é também acessado pela Secretaria Municipal de Obras, e esse uso comum é indicado pelo secretário de agricultura como parceria entre as duas repartições da administração municipal. Eventualmente são utilizados maquinários de demais agências governamentais por meio de convênios ou parcerias, como da EMATER-RJ, no âmbito do Programa Estradas da Produção.

A realização de obras, como a manutenção de estradas vicinais, é tratada pelos conselheiros como condição para a produção e comercialização agrícola e para o deslocamento dos moradores das áreas rurais. Para eles, é óbvia a responsabilidade da prefeitura municipal em conservar estradas, as quais compõem cerca de 500 quilômetros de malha viária. Por outro lado, cobrar a Secretaria de Agricultura por essa atuação da administração municipal é algo tido como um dos papéis dos conselheiros. Outro objetivo do programa, a oferta de serviços de máquinas agrícolas, é tratado pelos conselheiros como estímulo para a produção desse setor. Tal incentivo é condicionado às épocas de plantio e colheita, o que repercute em períodos de alta demanda por serviços. O programa oscila entre atendimentos individuais aos produtores rurais e realização de benfeitorias coletivas. Desse modo, as atividades da iniciativa adquirem destaque nas reuniões do conselho em vista dos produtores e localidades beneficiados com serviços de máquinas. Durante as discussões são conjugadas noções de favorecimento e descaso para determinados produtores e localidades, e são sobrepostos produtores "desfavorecidos" e localidades "abandonadas" pela administração municipal. Por outro lado, a utilização do maquinário pela Secretaria Municipal de Obras agrega considerações de descaso tanto com os produtores rurais quanto com a Secretaria de Agricultura.

Nas reuniões de janeiro, maio e setembro de 2013, o Programa Patrulha Mecanizada é discutido detidamente. No primeiro encontro, o programa é 
suscitado pelo secretário de agricultura com a proposta de rastrear as máquinas, e na reunião de maio, o assunto decorre de informe desse funcionário sobre a lei da piscicultura. Na reunião de setembro, a discussão é iniciada pelo secretário como item de pauta: trata-se de um projeto de aquisição de maquinário. O programa é retomado no decorrer dessa reunião por presidente de associação de moradores, na forma de demanda por realização de obras, e por dirigente de cooperativa, como questionamento quanto ao uso de maquinários. Durante os debates, a cada intervenção dos participantes do CMDR emergem concepções sobre o funcionamento do programa, são postos os interesses em jogo e delimitadas as atribuições do conselho, dos conselheiros e da Secretaria de Agricultura. Nessas reuniões são encenadas situações similares de interações entre mundos assimétricos (HEREDIA et al., 2012; L'ESTOILE, 2015; MOSSE, 2005; NEVES, 2010) que buscam intervir um no outro por meio de ideários de participação popular revestidos como ajuda ao município, escuta, atendimento e defesa dos produtores rurais.

A aquisição de maquinário e o controle dos serviços de máquinas são tratados detidamente na reunião de setembro. A reunião tendia a ser curta, pela previsão de três itens de pauta assim referidos pelo presidente do conselho: Sistema de Convênio, crédito agrícola da Caixa Econômica Federal e Dia de Campo da EMBRAPA. O primeiro item é apresentado pelo presidente, e o segundo e o terceiro, por funcionários da Caixa Econômica Federal e da EMBRAPA, respectivamente. Após a discussão desses itens, outras questões surgem entre os conselheiros. Eles abordam a "falta de ônibus", "ausência de atendimento odontológico", "assalto e roubo", "obra de drenagem em canal", "agradecimentos" e "pedido de cópia do processo da barragem do Guapiaçu”. A reunião prolonga-se com o surgimento de novas questões e, no caso da aquisição e uso de maquinário, os antigos problemas e interesses são refinados.

A aquisição de maquinário é assim registrada em ata:

O presidente iniciou a reunião agradecendo a presença de todos e apresentou as pautas do dia: aprovação de projeto para aquisição de 01 retroescavadeira e de projeto para aquisição de 01 patrol, projetos do SICONV [Sistema de Convênios do Governo Federal]. A aprovação é de grande importância para a agricultura, para a abertura de valas de drenagem, manutenção de estradas vicinais, abertura de tanques para piscicultura. Para aprovação dessas máquinas é necessária aprovação do conselho. Colocarei em votação com exclusividade dessas máqui- 
nas para agricultura. Por unanimidade os Conselheiros aprovaram a aquisição, através de projeto SICONV, de 01 (uma) retroescavadeira e 01 (uma) patrol (CMDR, 2013).

A brevidade do registro da ata condensa a questão e os problemas a serem resolvidos através do conselho, mas obscurece as discussões realizadas para se chegar à tomada de decisão. A proposta de aquisição de maquinário e sua aprovação são justificadas como "de grande importância para a agricultura”, são reforçadas pelos seus elementos condicionantes e adquirem tom decisivo nos termos: "Colocarei em votação com exclusividade dessas máquinas para agricultura”. Neste ponto da tomada de decisão, tanto os problemas em vista quanto a solução apresentada pelo presidente do conselho são referendadas pelos participantes do CMDR através da menção da aprovação do projeto de aquisição de maquinários.

A observação da dinâmica da discussão alarga os entendimentos sobre o processo de tomada de decisão e sobre a abrangência dos problemas e soluções. Ocorre, durante a discussão, a transformação da oferta de maquinário em demanda dos produtores rurais. Para essa alteração, a oferta de máquinas realizada por agências de governo é posta como intenção da Secretaria de Agricultura. Ao ser debatida, os conselheiros apropriam a oferta como demanda sob a justificativa de efetivo atendimento a produtores rurais.

O registro da reunião em diário de campo $^{10}$ possibilita acompanhar o desenrolar da discussão:

\footnotetext{
${ }_{10}$ A reunião foi iniciada com 30 minutos de atraso. Estavam presentes 14 conselheiros e outros dois chegaram após o começo da reunião. Notando a demora para começar o encontro, o representante do sindicato da agricultura familiar questiona o horário para a secretária executiva do conselho. Ela consulta o presidente do conselho e os três debatem a fórmula da contagem de quórum: "Iniciar na segunda chamada com qualquer número de conselheiros". O presidente chama a atenção de todos e explica a situação do quórum, iniciando então a reunião. Ao final da mesma, durante os informes, o representante do sindicato da agricultura familiar reclama do atraso dos conselheiros: "Chegam atrasados, falam, falam, falam e vão embora. Isso é para vocês pensarem, eu venho cedo para dar quórum”. A ocasião da reunião se torna uma atividade valorizada pelos participantes do conselho em vista das discussões em pauta, o que permite a visibilidade de determinados participantes conforme o público e o assunto da reunião. Aqueles que "falam, falam, falam" são criticados no pronunciamento do representante do sindicato, não por "falarem", mas por se ausentarem no decorrer da reunião, das ocasiões que se tornam menos valorizadas mas necessárias para apreciação pelo conjunto. Reuniões como a que tinha como item de pauta a construção de barragem em rio local contavam com três a quatro dezenas de participantes e, quando a discussão terminava, restava um terço dos mesmos. Essa mesma dinâmica ocorria em reuniões que tinham a presença do prefeito.
} 
O presidente do conselho inicia seu pronunciamento relembrando o trabalho do assessor de máquinas, cita a parceria com a secretaria de obras e a manutenção, "até o ano que vem", das estradas vicinais pela Secretaria de Agricultura. Relata o projeto para aquisição de duas retroescavadeiras para o município, cita as características das máquinas [marca e modelo], a capacidade de realizar drenagem e corte de saibro e pergunta aos presentes: "Qual a opinião de vocês?" Um senhor [Daniel, cerca de 60 anos, representante de associação de assentados de São José da Boa Morte] questiona se a retroescavadeira vai ser exclusiva da Secretaria de Agricultura. O presidente Robson responde afirmativamente e retoma o relato da parceria com a Secretaria de Obras; por fim, reforça que as máquinas devem estar na agricultura para a produção. O mesmo conselheiro questiona quem fará a limpeza das valas e a capina. O presidente responde que a limpeza das valas é atribuição da Secretaria de Agricultura, mas não responde quem deve realizar a capina. Dá a entender que a capina é responsabilidade do produtor. Marcelo [cerca de 50 anos, representante de associação de produtores de goiaba] pergunta: "É emenda parlamentar ou o quê?" Robson responde que são duas máquinas, uma vem do Ministério de Desenvolvimento Agrário e, outra, do Ministério da Agricultura, uma por deputado e outra por emenda, e convoca a votação. Um senhor [Augusto, cerca de 60 anos, representante de associação de moradores de Patis] questiona a quantidade de máquinas necessárias para atender à demanda. O presidente do conselho menciona de quatro a cinco retroescavadeiras para atender bem, diz que hoje tem duas ou três trabalhando. Diogo [cerca de 60 anos, representante de cooperativa de piscicultores e ranicultores] interpela, mencionando o Regimento Interno do conselho, se as estradas vicinais devam ser competências "deste espaço aqui". Relata que houve casos de pagamento de horas de máquina que não foram contemplados, que durante as eleições [municipais de 2012] foi feito atendimento político para uso das máquinas. Ele próprio havia comprado as horas de máquinas no ano anterior para abrir tanque para criação de peixe, mas não fora atendido. Em seguida sugere que deva haver algo estrutural para resolver a questão e pergunta aos presentes "O colegiado aqui deve chegar junto, fazer deste cenário algo contributivo, não é Chá das 5 de manhã cedo, o que a gente pode fazer para contribuir?" Robson diverge sobre a gestão anterior [derrotada nas eleições] e relata que as máquinas em questão vão chegar no início do próximo ano, e que mais outras chegarão, que a demanda é grande e muitos produtores não foram atendidos no ano anterior. Enfatiza que a patrulha mecanizada foi organizada em 2003 com limite de dez inscrições por máquina para agilizar o atendimen- 
to. Outro conselheiro [Euler, cerca de 60 anos, representante de sindicato de trabalhadores rurais] parabeniza o secretário de agricultura pela organização da patrulha. O presidente relata o período de oito meses do atual governo e salienta que não resolvem uma coisa de um dia para o outro. Cita o funcionário responsável pelo agendamento das máquinas, dizendo que ele está trabalhando com uma planilha para organizar melhor o atendimento. Um senhor [Miguel, cerca de 60 anos, representante de associação regional de piscicultores], afirma que as pessoas não foram atendidas por falta de máquinas, mas por preferências; diz ainda que as máquinas param porque faltam peças e manutenção, menciona que o prefeito viu em [na localidade] Maraporã o cemitério de máquinas. Bruno [cerca de 40 anos, representante de sindicato da agricultura familiar] relata que uma máquina foi usada em Papucaia para a campanha do ex-prefeito e reforça que as máquinas da agricultura devem ficar na agricultura. O presidente retoma a votação. Diogo o interrompe, em tom de desabafo: "Nós estamos ao lado de vocês, cúmplices". Ele propõe a melhoria organizacional da secretaria com mais transparência, "botar um quadro na Secretaria, atender até as pessoas políticas e especificar para ficar claro para nós e para quem nós representamos, não ser massa de manobra e ser mais consciente". Bruno o interrompe, perguntando "Três retroescavadeira trabalhando seis horas por dia, dá quanto por semana?” Diogo replica: "Vocês entendem o que eu quero? Quero que tenha transparência". Robson acata a sugestão do quadro e relata que há a lista com o ordenamento das horas das máquinas, que a ordem de atendimento segue de acordo com o pagamento no banco. Sublinha ainda que o relatório do uso das máquinas está quase pronto e que deverá apresentá-lo ao conselho trimestralmente, menciona o trabalho em mutirão [conjunto de máquinas como retroescavadeira, patrol e caminhão], a necessidade de ouvir os conselheiros e de resgatar a credibilidade do produtor. Diogo indaga a tolerância da Secretaria com as pessoas que não pagam a hora de trator e usufruem do serviço, Bruno diz que não devem prestar serviço a quem não paga: "A pessoa agenda o serviço na secretaria, não faz o depósito mas é atendido". Bruno ainda pondera: "Nós, conselheiros, devemos fazer nosso papel, de ver a pessoa que pede e não paga enquanto outro paga mas não leva". Ele enfatiza que as pessoas cobram, falam mal, "Fulano é péssimo secretário". O presidente salienta a mudança gradativa no governo e coloca a aquisição das máquinas em votação. Um senhor [Edson, cerca de 70 anos, representante de associação de moradores do Areal, Estreito e Matumbo] enfatiza: "Botar em votação as máquinas com exclusividade para a Secretaria de Agricultura." Todos levantam a mão e o presidente dá 
por aprovada a aquisição das máquinas (PRAZERES, Luciano Padilha dos. Notas de campo. 02 set. 2013).

A dinâmica da discussão ocorre com a contextualização de problemas e o apontamento de soluções. O trabalho do assessor de máquinas, a parceria com a Secretaria de Obras e a manutenção das estradas vicinais pela Secretaria de Agricultura serve ao presidente do conselho como pretexto para apresentar o projeto de aquisição de máquinas. Essa maneira de relatar o par problema/solução escapa de uma linguagem burocrática e tende a se aproximar da vivência dos participantes do conselho (COMERFORD, 2003; HEREDIA et al., 2012; L'ESTOILE, 2015). Assim, o projeto relatado volta-se para os bens e suas aplicações. A maneira de dispor a decisão para os conselheiros evoca uma relação de proximidade entre presidente e conselheiros: "Qual a opinião de vocês?” Até então, a tomada de decisão é sobre a intenção da secretária de agricultura e são os interesses da Secretaria de Agricultura que estão em jogo no conselho. Entretanto, os sentidos dos problemas, soluções, interesses e intenções são ampliados com as intervenções dos conselheiros.

A pergunta do representante de associação de assentados, Daniel, reforça a importância dada às máquinas para usufruto da Secretaria de Agricultura ao lançar mão do termo "exclusivo". Ele põe em evidência o uso das máquinas para atender os produtores rurais em contrapartida ao uso pela Secretaria de Obras. Robson reconsidera a parceria com esse órgão e frisa o atendimento direcionado aos produtores. Ele age de modo a mediar os interesses de produtores rurais e da administração pública. O mesmo representante põe em cena os problemas latentes para o uso das máquinas, o que, de acordo com o presidente, é passível de solução com os bens em questão. Com os problemas levantados por Daniel, os interesses de produtores rurais e da Secretaria de Agricultura integram-se parcialmente em torno de objetivos comuns.

Com a intervenção do representante de associação de produtores de goiaba, há uma mudança no sentido da aquisição das máquinas, por meio de uma pergunta sobre a maneira de obter o maquinário. A resposta do presidente demonstra o alinhamento da intenção da Secretaria com agências de governo federal através de deputado e emenda ${ }^{11}$. Neste entendimento, o pro-

${ }^{11}$ Quanto à ligação entre distintas esferas de governo e mediação de demandas locais e interesses políticos pela atuação parlamentar, ver Bezerra $(1999,2001,2006)$. 
jeto SICONV redigido na ata é então religado com a atuação de parlamentar e de agências federais de governo e, desse modo, interesses de outrem permanecem subjugados à discussão do projeto no conselho (BEZERRA, 2001; HEREDIA et al., 2012; L'ESTOILE, 2015; MOSSE, 2001, 2005). Ao passo que o presidente tenta seguidas vezes convocar a votação, os interesses dos conselheiros vão sendo esclarecidos através do norteamento dos problemas que a proposta visa a resolver. O modo de tratar da aquisição de maquinário paulatinamente confere o sentido da oferta de agências de governo para o sentido de demanda dos produtores rurais, o que acaba por obscurecer os propósitos da Secretaria de Agricultura, como também de parlamentares e demais agências de governo. O interesse da Secretaria e a origem do maquinário são minimizados quando os conselheiros tratam da defesa dos interesses dos produtores rurais, quando focam nos problemas do atendimento a produtores. Nesse ínterim, o secretário de agricultura demonstra a valorização das expectativas dos produtores rurais como forma de garantir objetivos da administração pública.

As intervenções subsequentes são entendidas como configurações das demandas dos produtores rurais. Uma primeira trata de medir a atenção aos produtores, o que acaba por reforçar a necessidade de obter mais máquinas. Uma segunda intervenção é eloquente. O representante de cooperativa de piscicultores, Diogo, tem como questão o efetivo atendimento a produtores rurais e, para introduzir essa questão, ele contesta as atribuições do conselho, como que para reafirmar as competências dos conselheiros. Para além da prescrição regimental, as competências dos conselheiros devem ao menos influir, "chegar junto, fazer algo contributivo", sobre as atividades da Secretaria de Agricultura. A atribuição dos conselheiros volta-se para a verificação das demandas dos produtores rurais, o que é exemplificado in loco com o próprio caso do representante da cooperativa. Além de examinar as demandas, os conselheiros devem observar a própria utilização do maquinário, para saberem se ocorre o "atendimento político". Desse modo, a questão "estrutural" posta por Diogo pode ser entendida como verificação das demandas e da utilização das máquinas através da palavra-chave "transparência". O pronunciamento desse interlocutor não se pauta somente por suas expectativas frustradas, mas ascende à representação dos produtores rurais não contemplados 
pelos serviços da Patrulha Mecanizada. Nesse sentido, o espaço do conselho é conclamado como espaço contributivo para a gestão da Patrulha Mecanizada.

Mesmo com a presteza do secretário e do chefe de equipe em atender os produtores, a demanda por serviços de máquinas e a utilização do equipamento permanecem como "problema estrutural". Os produtores rurais não atendidos pelo serviço de maquinário se fazem representados (BOURDIEU, 1989) na cena do conselho através de Diogo, ação reforçada com as condutas de Miguel e Bruno. Os dirigentes da cooperativa de piscicultores, da associação de piscicultores e do sindicato da agricultura familiar engajam-se na discussão demonstrando apoio mútuo, como que sustentando o palanque de Diogo. Miguel trata de uma versão do atendimento político, as "preferências" em contraste com a falta de máquinas. Bruno aborda outra versão do atendimento político, o uso de máquinas para campanha eleitoral. Com esses suportes, Diogo enaltece a condição de cumplicidade dos conselheiros frente ao conjunto de problemas apresentados. Essa condição nivela os conselheiros e dispersa as responsabilidades de representantes da sociedade civil junto à administração pública, o que expõe uma relação de dependência entre atores da sociedade civil e do poder público com preponderância destes.

A proposta de Diogo redefine o sentido das responsabilidades dos representantes da sociedade civil frente ao poder público: "Não ser massa de manobra e ser mais consciente". Outra proposta tende a resguardar tanto as responsabilidades dos conselheiros quanto as do secretário com a possibilidade de verificação do atendimento aos produtores rurais: "Botar um quadro na Secretaria, atender até as pessoas políticas e especificar para ficar claro para nós e para quem nós representamos". Desse modo, a verificação por um quadro se torna o mecanismo que tende a isentar as responsabilidades de conselheiros e secretário por distorções do atendimento aos produtores. $\mathrm{O}$ "quadro", a "planilha", a "lista" e o "relatório" se tornam os meios que transfiguram a "transparência" da gestão do Programa Patrulha Mecanizada, o que possibilitaria examinar o atendimento aos produtores rurais, saber quem foi, quem está sendo e quem será atendido, onde estavam, onde estão e onde estarão as máquinas.

A resolução do "problema estrutural" altera-se na linguagem do dirigente da cooperativa e do presidente do conselho ao focar na atenção dada aos produtores rurais. O primeiro trata do quadro, enquanto o segundo cuida 
da planilha, lista e relatório. A distinção vocabular ocorre no modo de expor informações mas confere peso simbólico para o termo "transparência" ao possibilitar a evidência da ordem e da organização do atendimento. A solução proferida por Robson escapa do desejo de Diogo, não conquista a credibilidade do produtor. O "problema estrutural" é mantido em vista pelo representante da cooperativa e pelo representante do sindicato com as distorções dos meios de executar o atendimento ("Agenda, não paga, mas é atendido."). Para que haja transparência, não bastam elementos que ordenem o atendimento, mas, pelas assertivas de Diogo e Bruno, é necessária a intolerância para a execução do atendimento. Nesse ínterim, os interesses do presidente e dos dirigentes da cooperativa e do sindicato voltam-se para os mesmos objetivos mas não coincidem entre si.

Além dos elementos de ordem impessoal, técnica ou burocrática, questões de ordem pessoal, da reputação, entram em jogo na avaliação da atuação do secretário e dos conselheiros. O dirigente do sindicato da agricultura familiar clama pela dedicação dos conselheiros e pela dedicação do secretário face aos problemas levantados sob o risco da cobrança, de "falar mal". Tanto o governo, ou especificamente os atores sociais que são seus integrantes, quanto os conselheiros incorporam noções do papel a ser desempenhado e noções de competência, da habilidade de tratar um assunto como merecedor de atenção. A partir do desempenho de suas atuações decorre a avaliação ou o julgamento em vista dos representados. Assim, governo e conselho acabam por compartilhar preocupações em comum.

No momento da tomada de decisão, o representante do governo e os representantes dos produtores rurais executam detidamente seus papéis: o presidente convoca a votação, um conselheiro redefine os termos da votação, os conselheiros votam e o presidente oficializa o resultado da votação. Os conselheiros desenvolvem seu papel desse modo: apreciam o projeto da Secretaria de Agricultura, debatem sua relevância e o incorporam como demanda dos produtores rurais. Ao absorver a intenção da Secretaria de Agricultura como demanda, os conselheiros desempenham a competência para alterar o projeto, determinando condições e finalidades para sua aprovação. O presidente acata tacitamente as condições e finalidades para obter a aprovação, sujeitando-se ao conselho para ter seus interesses garantidos. 
Ao final da mesma reunião, quando da abertura para explanações dos conselheiros, as questões anteriormente levantadas são retomadas. Desta vez são os conselheiros que levantam questões para serem apreciadas pelo secretário de agricultura. Nesta ocasião, os participantes fazem considerações sobre as obras concluídas, tais como a reforma de dique e o patrolamento de estradas, atos pelos quais a Secretaria de Agricultura é parabenizada. Também apontam as obras a serem realizadas. O presidente do conselho responde aos questionamentos considerando os problemas e as soluções para a realização das obras. Novamente, conselheiros e presidente entram em acordo sobre o que fazer e como fazer para garantir o atendimento aos produtores rurais. Entretanto, do fundo do auditório, em pé e em alto tom de voz, Diogo chama a atenção de todos. Ele discorre sobre máquinas específicas para as atividades de piscicultura.

O presidente da cooperativa, já à frente da sala, cobra a destinação da escavadeira hidráulica e do trator de esteira para os produtores rurais e propõe o cadastro de piscicultores do município. O presidente do conselho volta-se para os conselheiros explicando a aquisição dos equipamentos citados:

"As máquinas foram compradas pelo Ministério da Pesca e doadas para as prefeituras, o Vinícius [secretário municipal de planejamento] foi à Brasília para ver com o Ministro [Marcelo] Crivella [ministro da pesca], o Felipe Peixoto [secretário estadual de desenvolvimento regional, abastecimento e pesca] foi também."

O presidente é novamente interrompido pelo representante da cooperativa. Ele encontrava-se em pé, próximo ao presidente e, dirigindo-se ao público, interpela a responsabilidade dos conselheiros: "Ganhar e não poder usar é desagradável”. Os representantes da associação de produtores de goiaba e do sindicato da agricultura familiar, Marcelo e Bruno, juntam-se ao debate dando suporte ao dirigente da cooperativa. Eles tratam de ações já tomadas para o incentivo à piscicultura, como cadastro de piscicultores e capacitação de mão de obra. O presidente do conselho põe termos finais à discussão, salientando a comprovação do cadastro e da capacitação, os requisitos para o licenciamento ambiental e o início breve do trabalho de abertura de tanques. Em seguida, passa a tratar dos informes. 
Nesse ínterim, a proposição e a apreciação dos assuntos colocados são invertidas. Os conselheiros levantam temas para serem estudados pelo presidente do conselho e, nessa dinâmica, esforçam-se para terem seus interesses garantidos. No primeiro momento, a demanda por realização de obras está em consonância com as intenções do secretário de agricultura, o que é dado sob a forma de acordo a respeito do que será feito. No segundo momento, a demanda por incentivo às atividades da piscicultura é levantada de maneira contraditória. Cobra-se a destinação de máquinas e a execução de atividades burocráticas, tendo-se em vista a obtenção de equipamentos e o cadastramento e capacitação de piscicultores. O presidente dessa cooperativa age de forma a reforçar uma demanda prévia e em execução, tornando-a algo a ser lembrado, esclarecido e apropriado ao conselho, tanto que o presidente do conselho encerra a discussão em termos consensuais, assentando-se nos termos postos pelos representantes da cooperativa, da associação de produtores e do sindicato da agricultura familiar sobre o que será feito brevemente.

O desenrolar das discussões sobre as atividades do Programa Patrulha Mecanizada tende a conservar a interação focada no presidente do conselho e a alternar os pronunciamentos entre ele e os conselheiros. Contudo, a dinâmica dos debates altera-se a partir da comoção sobre os problemas públicos, quando a provocação e a reafirmação de competências de atores e espaços sociais se erguem na defesa de pontos de vista sobre os problemas e os meios de sua resolução. $O$ foco da interação é centrado nas figuras que encarnam o problema público: um indivíduo que propriamente contesta uma questão e outro capaz de resolvê-la. Demais intervenções aglutinam-se em torno dessas figuras. A discussão muda seu foco, indo do presidente para conselheiro, concentrando-se neste. Demais conselheiros tomam partido para sustentar interesses homólogos. Enquanto isso, a representação de um segmento social, dos piscicultores, acaba por se fortalecer perante as demais, abrindo espaço para sua circunscrição como agente mobilizador de atenção. O caráter efusivo da discussão não impede as tentativas de conciliação de interesses. Ao contrário, os pontos de vista conflitantes são enredados sob o emblema da defesa dos interesses dos produtores rurais.

Os assuntos debatidos ao final da reunião fazem com que o par problema/solução se altere. Nas primeiras discussões são postos problemas a serem resolvidos no conselho, e nas últimas, aqueles a serem solucionados pela Se- 
cretaria de Agricultura. Os conselheiros atestam o domínio sobre os assuntos tratando-os de duas formas: através do levantamento de problemas dos produtores rurais como responsabilidade dos conselheiros e com a destinação da resolução dos mesmos problemas como responsabilidade da Secretaria de Agricultura. Os interesses dos conselheiros são efetivados através da representação dos produtores rurais. Por essa representação acabam sendo contempladas as pretensões dos produtores de determinadas áreas e atividades agrícolas $^{12}$. Ainda assim, os interesses de agricultores e de piscicultores são especificados sob o mote da representação dos produtores rurais. Portanto, não basta adquirir maquinário, mas sim dispô-lo a serviço dos produtores rurais. O presidente do conselho demonstra o reconhecimento de suas responsabilidades ao acatar e reforçar os mesmos problemas enquanto faz uma adequação da narrativa sobre as soluções e se previne com ressalvas sobre as condições para a execução das atividades com maquinário. Ele procura contemplar os interesses dos lavradores e dos piscicultores sob o mesmo signo de atendimento aos produtores rurais, ato pelo qual as intenções da administração pública e de suas repartições se submetem para serem asseguradas. Esse conjunto de interesses forma a tônica do conselho em dar destino às atividades da agricultura no município, o que reverbera o emblema da "exclusividade" para esse setor, especificamente.

Na cena do conselho ocorre a reafirmação da defesa dos interesses dos produtores rurais no que diz respeito à disposição do serviço de maquinário e do atendimento aos produtores. Quanto ao maquinário, os participantes reforçam seu usufruto "com exclusividade para a agricultura", em detrimento da Secretaria de Obras. Em relação ao atendimento aos produtores rurais, os participantes reiteram a prerrogativa de atender os produtores em detrimento da falta de atendimento e do "atendimento político".

A defesa dos interesses dos produtores rurais engloba, ainda, os distintos tipos de máquinas e sua utilização para obras coletivas e particulares. Demarca-se, por exemplo, o uso de escavadeiras hidráulicas ou de retroescavadeiras para limpeza de canal ou para abertura de tanque de peixe. Por

\footnotetext{
${ }_{12}$ Em reuniões seguintes, a piscicultura e ranicultura são discutidas como setor produtivo distinto da agricultura, especificamente como aquicultura. Essa distinção ocorre principalmente com a atuação de funcionários da Secretaria de Pesca do Estado do Rio de Janeiro, que profere uma palestra sobre esse tema no CMDR.
} 
outro lado, a defesa dos interesses dos produtores rurais ressoa na defesa dos propósitos da Secretaria de Agricultura, no que tange às intenções de adquirir maquinário.

Nesse caso, os interesses reforçam-se mutuamente, são tidos como tácitos. Em relação à utilização do maquinário, divergem quanto à concorrência entre repartições municipais e nas visões dos problemas e soluções, especialmente do efetivo atendimento aos produtores. Interesses e problemas comuns passam a ser diferenciados pela própria interpretação das questões, o que os diversifica e refina. Tem-se, no desenrolar das discussões, um conjunto de interesses que comungam entre si, tornam-se homólogos e divergem, com a submissão de um ao outro quando entram em conflito aberto ou latente.

\section{CONSIDERAÇÕES FINAIS}

Ao analisar as discussões empreendidas em torno do Programa Patrulha Mecanizada no Conselho Municipal de Desenvolvimento Rural de Cachoeiras de Macacu, percebo que este é um espaço que trata de questões importantes para a administração municipal e para os produtores rurais. Cada integrante, à sua maneira, levanta assuntos que requerem a atenção dos demais e instiga questões para serem apreciadas pelo conjunto de participantes. No decorrer das discussões, os representantes dos produtores rurais estipulam suas responsabilidades em torno do levantamento de demandas e de seu encaminhamento para resolução pelo representante do poder público, cujas responsabilidades concentram-se no acolhimento e resolução das demandas dos produtores rurais. As discussões geram a responsabilização ao tornarem as informações públicas (BOURDIEU, 2014), de conhecimento mútuo. Ao serem discutidos os bens, usos e beneficiários do Programa Patrulha Mecanizada, a construção daquelas responsabilidades é rearranjada em vista da situação de "cumplicidade" e da atuação "consciente" dos participantes, fatos pelos quais são refinados os interesses em jogo.

Os propósitos dos produtores rurais perfazem o fomento à produção agrícola e melhoramento das condições de vida da população rural. São unificados na ideia de ajudar o município, com incentivo e apoio das atividades 
dos produtores rurais. Também há a percepção de auxílio à administração municipal para prestação de serviços direcionados a eles e à população rural. Sustentam-se, assim, o mote da importância da agricultura na economia do município e o mote da defesa dos interesses dos produtores rurais. Contudo, o refinamento dos propósitos acaba por destacar a defesa de determinadas atividades agrícolas e localidades, o que põe em concorrência produtores e localidades atendidas pela administração pública, e destaca também a preponderância dos serviços públicos, o que alcança as agências de governo em concorrência quanto à prestação de serviços para a população rural. A atuação do presidente do conselho tende a resguardar os serviços da Secretaria Municipal de Agricultura face às demais repartições municipais e tende a reconhecer os interesses dos produtores rurais como legítimos, o que reforça a importância da área agrícola e desses trabalhadores.

Para os conselheiros representantes das entidades parceiras e da categoria "agricultores familiares", o conselho se torna um espaço de apreciação das atividades da Secretaria de Agricultura e de exposição dos problemas enfrentados pelos produtores rurais. O engajamento dos conselheiros baseia-se na tônica de ajuda ao secretário como princípio de mobilização e na colaboração através da especificação das atividades a serem executadas ou aprimoradas. Por um lado, a atuação dos conselheiros se faz com a indicação de problemas e soluções e, por outro, a atuação se dá com a exigência de posicionamento ou "resposta" do secretário. Desdobra-se dessa atuação dos conselheiros o engajamento na forma de contribuição ou na forma de reivindicação. Resta a estes a confecção de demandas passíveis de serem atendidas pela administração municipal, o que as caracteriza através da visualização dos possíveis ganhos (MOSSE, 2001, 2005).

O conselho se torna, para o secretário de agricultura, um espaço de referendo dos interesses da administração pública. Neste sentido, o secretário esforça-se para tornar possível a conciliação entre os interesses da administração municipal e dos produtores rurais. Contudo, o estímulo à vocalização dos conselheiros gera o refinamento dos interesses, o que os desdobra dos termos acordados tacitamente em conflitos em torno da interpretação dos problemas e soluções (MOSSE, 2001, 2005). Assim, as propostas e relatos apresentados pelo secretário cedem espaço para questões trazidas pelos produtores rurais, as quais são esclarecidas pelo conjunto de conselheiros e atribuídas como fa- 
tos de conhecimento por parte do secretário. Resta ao secretário a conversão das informações em atos de governo, o que repercute na tradução das discussões conforme os objetivos dos agentes de governo (MOSSE, 2001, 2005).

As reuniões do CMDR funcionam como um ritual de pacificação e uma técnica política (L'ESTOILE, 2015). Elas demonstram que situações similares de discussão se desdobram em momentos de conflitos para além daqueles que a reunião visa a resolver, em momentos em que a cooperação cede espaço para a disputa entre visões do que devam ser os atos de governo. Afinal, serviços de governo não são simples serviços, são serviços que servem para governar (FERGUSON, 1994, p. 253). Como observado nas discussões sobre aquisição e destinação de maquinário, o conflito se torna aberto em vista dos interesses mobilizados. Passa-se, nessas ocasiões, da generalidade do assunto e de seus acordos tácitos para suas particularidades, logo, voltando-se para generalizações quanto aos interesses legítimos e quanto aos modos da Secretaria de Agricultura prestar seus serviços. Nesses casos são mantidos em vista julgamentos impessoais e pessoais quanto à conduta dos atores sociais envolvidos, o que resulta o julgamento da capacidade, atribuição, "tolerância", "cumplicidade" e da "consciência", o fortalecimento do "papel do conselheiro" e da "responsabilidade do conselho". Por meio dessa forma de gestão de conflitos, o CMDR adquire importância no cenário municipal como um conselho "que briga", "que faz", "que chega junto", e não um "Chá das 5", o que repercute na reputação dos produtores rurais e do secretário de agricultura como atores sociais hábeis para confecção da política agrícola municipal.

\section{REFERÊNCIAS BIBLIOGRÁFICAS}

1. ABRAMOVAY, Ricardo. Conselhos além dos limites. Revista de Estudos Avançados. Dossiê Desenvolvimento Rural. São Paulo, USP, v. 15, n. 43, p. 121141, set/dez. 2001.

2. AVRITZER, Leonardo (Org.). A dinâmica da participação local no Brasil. São Paulo: Cortez, 2010.

3. BECKER, Howard. Métodos de pesquisa em ciências sociais. São Paulo: Hucitec, 1997. 
4. BEZERRA, Marcos O. Em nome das "bases": política, favor e dependência pessoal. Rio de Janeiro: Relume Dumará, 1999.

5. BEZERRA, Marcos O. O “caminho das pedras": representação política e acesso ao governo federal segundo o ponto de vista de políticos municipais. In: PALMEIRA, M.; BARREIRA, C. (Orgs.). Política no Brasil: visões de antropólogos. Rio de Janeiro: Relume Dumará, 2006.

6. BEZERRA, Marcos O. Políticos, representação política e recursos públicos. Horizontes Antropológicos, Porto Alegre, v. 7, n.15, p. 181-207, julho 2001.

7. BOURDIEU, Pierre. A delegação e o fetichismo político. In: BOURDIEU, P. Coisas Ditas. São Paulo: Editora Brasiliense, 1989.

8. BOURDIEU, Pierre. Sobre o Estado: cursos no Collège de France (1989-92). São Paulo: Companhia das Letras, 2014.

9. CMDR. Ata Reunião Ordinária. Cachoeiras de Macacu, 02 set. 2013. Mimeografado.

10. COMERFORD, John C. Como uma família: sociabilidade, territórios de parentesco e sindicalismo rural. Rio de Janeiro: Relume Dumará, 2003.

11. DAGNINO, Evelina (Org.). Sociedade civil e espaços públicos no Brasil. São Paulo: Paz e Terra, 2002.

12. FERGUSON, James. The anti-politics machine. "Development", depoliticization and bureaucratic power in Lesotho. Minneapolis and London: University of Minnesota Press, 1994.

13. GOHN, Maria da Glória. Conselhos gestores e participação sociopolítica. São Paulo: Cortez, 2011.

14. HEREDIA, Beatriz Maria Alasia de.; BARREIRA, Irlys Alencar Firmo; BEZERRA, Marcos Otavio; PALMEIRA, Moacir; CORADINI, Odaci Luiz. (Orgs.). Política, governo e participação popular: conselhos, orçamento participativo e outras experiências. Rio de Janeiro: 7 Letras, 2012.

15. L'ESTOILE, Benoît. A reunião: ferramenta e ritual de governo. Relações pessoais e mundo do Estado num assentamento da Zona da Mata de Pernambuco. Revista Antropolítica, Niterói, n. 39, p. 248-282, $2^{\circ}$ sem. 2015.

16. MOSSE, David.Cultivating development. An ethnography of aid policy and practice. London and New York: Pluto Press, 2005.

17. MOSSE, David. "People knowledge", participation and patronage: operations and representations in rural development. In: COOKE, B.; KOTHARI, U. (Orgs.). Participation: the new tyranny? Nova York: Zed Books, 2001. 
18. MOURA, Joana T. V. Conselho Municipal de Desenvolvimento Rural e Agricultura Familiar. A representação de interesses em perspectiva. In: CONGRESSO BRASILEIRO DE SOCIOLOGIA, 12., 2005. Belo Horizonte. Anais... Belo Horizonte: SBS, 2005, p. 1-24.

19. NEVES, Delma P. Políticas públicas: interações previstas e desdobramentos inesperados. Ciências Sociais Hoje, v. 1, p. 48-85, 1993.

20. NEVES, Delma P. Políticas públicas: mediação e gestão de demandas sociais. Retratos de Assentamentos, Araraquara, n.13, p. 171-206, 2010.

21. PRAZERES, Luciano Padilha dos. Notas de campo. 02 set. 2013.

22. ROMANO, J.; DELGADO, N. G. Os planos municipais de desenvolvimento rural como processos sociais. In: ROMANO, J.; DELGADO, N. G. Mundo rural e cultura. Rio de Janeiro: Mauad, 2002.

Recebido em 30 de janeiro de 2019

Avaliador A: 20 de março de 2019

Avaliador B: 05 de abril de 2019

Aceito em 19 de junho de 2019 